\title{
Misalignment and Unbalance Fault Severity Estimation using Stator Current Measurements
}

\author{
Bram Corne, Jos Knockaert and Jan Desmet \\ Department of Electrical Energy, Metals, Mechanical Constructions and Systems (EEMMeCS) \\ Faculty of Engineering and Architecture (FEA), Ghent University \\ Graaf Karel de Goedelaan 34, B-8500 Kortrijk, Belgium \\ email: Bram.Corne@UGent.be
}

\begin{abstract}
The feasibility of using stator current measurements in order to detect mechanical problems in electric rotating machinery has been proven by many authors several decades ago. However, this way of detecting problems has never been exploited as a full-covering and reliable prognostic monitoring technology. Although the imposed current-signatures of different evolving mechanical faults in electric machines are well characterized, the relation between the severity of those faults and the corresponding faulty signatures is still not elucidated thoroughly. As the authors built an innovative test-rig on which all kinds of mechanical faults can be emulated with a wide variety of controllable environmental conditions, those specific relations can finally be investigated. The test-rig contains an $11 \mathrm{~kW}$ induction machine with an integrated active magnetic bearing at drive-end side. The magnetic bearing can easily manipulate the rotor's position corresponding to a real manifesting and evolving mechanical fault with a high accuracy and reproducibility. In this paper, the relation of the current fault-signatures and the severity of misalignment and mechanical unbalance is investigated. After theoretically describing the different eccentricity-related rotorfaults, the faults are induced and emulated on the induction machine under test. The fault-components in the stator currents' spectra are monitored while the severity of the faults is being increased. By fitting corresponding trending-functions on the obtained results, the severity of misalignment and unbalance can be estimated out of stator current measurements.
\end{abstract}

Index Terms-Condition monitoring, Fault diagnosis, Induction motors, Emulation, Ball bearings

\section{INTRODUCTION}

Using the stator current of electric rotating machinery in order to perform Condition Monitoring (CM) has gained a lot of interest the last decades [1]-[10]. Reasonably, because the CM-technology is cheap, robust, both electrical and mechanical faults can be detected, easy to implement... For the rather new CM-technology to be successful on the market of predictive and/or prognostic maintenance, only one keyproperty is required: reliability. The CM-technology must guarantee that every machine-problem is identified before an unexpected machine-failure can occur. By identifying is intend that the type of problem must be diagnosed (e.g. broken rotor bar, stator winding shortcut, bearing inner race problem) as well as the severity of the issue. The severity-estimation is crucial, as the machine's operator must be able to estimate how urgent the problem should be handled based on how fast the problem can lead into an unexpected breakdown. It

978-1-5090-0409-6/17/\$31.00 @ 2017 IEEE would be exaggerated if an entire production process has to be shut-down because a minuscule mechanical mass-unbalance is detected. However, it is in fact the mechanical severityestimation which is still lacking in the nowadays CM-systems based on current measurements. Therefore, using the stator current as a complete and reliable CM-technology remains unserviceable. The only way to overcome these issues is to obtain a clear and thorough view on the specific relation between the severity of mechanical faults and their reflection in the stator current. Therefrom, a lot of research has been conducted world-wide in order to emulate mechanical faults on electrical machinery with high accuracy and reproducibility. Unfortunately, most emulating-methods have short-comings on reproducibility and are consequently unable to obtain the desirable links. For example, regarding bearing faults, the generally applied method is replacing one of the bearings of the machine under test by a bearing suffering from an artificial implemented fault, [3], [4], [6]-[9], [11]. That method satisfies the need of proving the feasibility of some technologies, but is inadequate to perform detailed, reproducible research on condition monitoring technologies. The reproducibility is unfortunately lost by remounting the bearing, as system characteristics such as stiffness and damping are highly depending on the bearings' mounting and have a severe impact on the machine's faulty behavior, [7], [12], [13]. A new way of emulating mechanical faults on electrical machines is needed in order to obtain a reliable current-based CM-system.

Driven by this problem-statement, the authors constructed an innovative mechanical fault-emulator, [14]. This emulator contains an $11 \mathrm{~kW}$ Induction Machine (IM), mechanically connected to a torque-controlled load-machine (DC-machine, $22 \mathrm{~kW}$ ). The Drive-End (DE) bearing of the IM is replaced by an Active Magnetic Bearing (AMB). Instead of using the AMB to keep the rotor perfectly centered with respect to the stator, the AMB is used in order to induce some artificial rotor-movements. As most mechanical faults create a specific deviation between the rotor and the stator (e.g. bearing faults, unbalance, misalignment), they can be reproduced by emulating those rotor-movements in an IM. Consequently, when these mechanical faults are characterized by a specific displacement between the rotor and stator, they can serve as set-points for the AMB, [14]. By implying the fault-related rotor-movements in the IM, a highly reproducible mechanical fault-emulator is obtained. Because the AMB is controlled by 
a real-time controller, the fault-severity can be adapted online while other operational parameters (e.g. speed, torque, temperature) are stabilized. Additionally, the stiffness and damping characteristics of the AMB can be adapted to the mechanical properties of the original mechanical bearing. This implies that the operational character of the IM is not subjected to the AMB. The most challenging part in this novel approach is characterizing the movements between the rotor and stator under faulty conditions. Those movements regarding bearing-problems are analytically obtained and validated in [14]. However, the focus in this paper is on eccentricities, more specific: misalignment and mechanical unbalance.

The origin and characterization of the specific rotormovements when misalignment and/or mechanical unbalance occur is handled in $\S I$ II. Those movements will serve as setpoints for the AMB, which is briefly discussed in §III. As the $\mathrm{AMB}$ is implemented and the rotor-movements are obtained, experiments are conducted. The relation between misalignment/unbalance and the stator current's frequency components is measured, analyzed and discussed in §IV. Conclusions regarding this paper and a view on future research can be found in $\S \mathrm{V}$.

\section{ECCENTRICITY IN ROTATING ELECTRIC MACHINERY}

Eccentricity is an unavoidable phenomena in rotating electric machinery. First, a distinction is made between static and dynamic eccentricity, visualized in Figure 1, [15]-[18]. Regarding static eccentricity, the rotor is rotating around its own gravitational center, but deviated with respect to the center of the stator. With dynamic eccentricity, the rotor is rotating around the center of the stator, but deviated with respect to the gravitational center of the rotor. Once an eccentricity occurs which is a combination of both static and dynamic eccentricity, it is called mixed eccentricity.
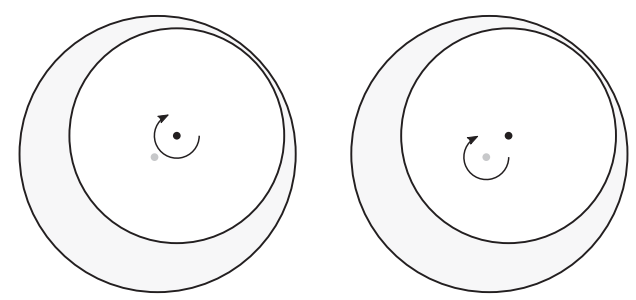

Figure 1: Static eccentricity (left) and dynamic eccentricity (right)

Both static and dynamic eccentricity are mainly imposed by respectively excessive static and/or dynamic radial forces on the machine's bearings, [15], [17], [18]. Once the bearings fail due that load, the rotating machine will break down and -depending on the application of the equipment- serious economic damage can be caused. A few examples of excessive radial overload and its consequences is presented in Figure 2, [19]. Obviously, radial forces and eccentricities should be avoided in any rotating application.

Radial forces are commonly generated by any belt- ,chainor gear-transmission. However, if the machine is correctly dimensioned for its application, this should not cause unacceptable eccentricities. The main causes of excessive eccentricity can be found in misalignment and mechanical unbalance.
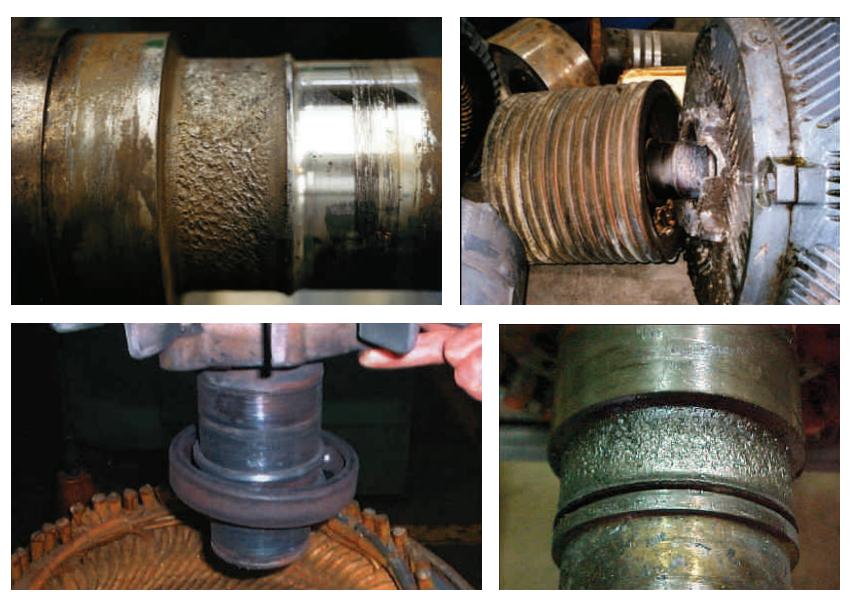

Figure 2: An excess of radial forces can have a serious impact on rotating machinery, [19]

Because of misaligning one machine with another (or one rotor with another), unpredictable and mainly underestimated radial forces are exposed on the bearings of both machines. In addition, mechanical unbalance can cause as well significant dynamic radial loads and so rotor-eccentricities. Furthermore, once an eccentricity (static or dynamic) is imposed onto the machine, the Unbalance Magnetic Pull (UMP) severely increases the magnitude of the eccentricity, [15]. As these two main causes of implied eccentricity can easily induce serious trouble with the machine's robustness and reliability, detecting misalignment and mechanical unbalance on industrial drivetrains is very valuable. Consequently, in the industrial and academic field, a lot of effort has been made in order to detect eccentricities on several ways: vibration analysis, current signature analysis, acoustic analysis, flux analysis... As the authors of this paper are focused on applying Motor Current Signature Analysis (MCSA) as a complete and reliable condition monitoring technology, only relations between eccentricity and its reflection in the stator's current is examined.

As previously mentioned, the intension of the faultemulating test-rig is manipulating the rotor's position in relation to the stator's position. Therefore, specific information is needed on the rotor-movements under faulty conditions. The following sections handle respectively the induced rotormovement when misalignment and mechanical unbalance occur. The rotor-deviation (or eccentricity) is analytically expressed in such a way that the severity of the fault can easily be increased on the test-rig while the current signatures are analyzed.

\section{A. Misalignment}

Misalignment is a term given to the error in the alignment between two rotating shafts, which is commonly used in positioning electric machines coupled with a certain load machine (fans, gearboxes, pumps...). Misalignment is divided in three main categories: parallel (or lateral), angular and combined misalignment. Those groups can each be subdivided by the horizontal and vertical misalignment. Figure 3 represents these groups of misalignment in a two-dimensional plane. It must be noticed that misalignment does not directly imply a failing 
of one of the coupled rotating machines, but the bearings of the coupled machines can be subjected to heavy static and/or dynamic loads which can easily lead into an unexpected premature failure. It has to be noted that, in every application, combined misalignment is always present as perfect alignment is practically nonexistent. Nevertheless, it is comprehensible that a small amount of misalignment does not directly threaten the health-condition of the machine. Consequently, a lot of companies have build (mostly based on experience) tolerancetables in order to quantify the acceptance of angular and parallel misalignment.

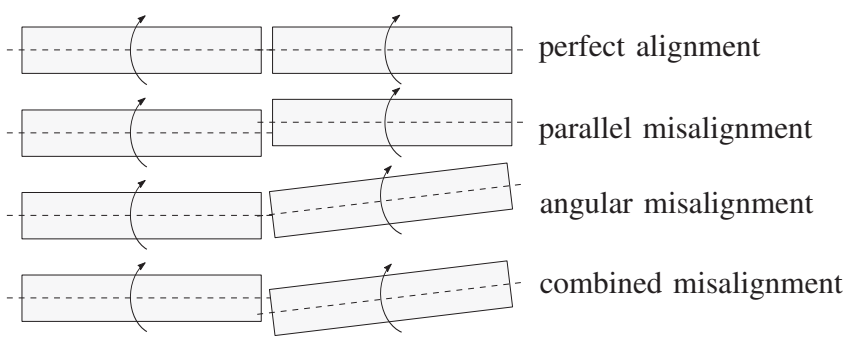

Figure 3: Misalignments of two rotating shafts

Emulating misalignment in an academic environment is technically possible by rearranging the IM in reference to the load (a DC-machine). This is however not very easy and adequate to imply a specific quantified misalignment when it comes to several $\mu \mathrm{m}$. Although only combined misalignment can be imposed, the AMB can displace the radial position of the rotor in relation to the stator at DE-side with an accuracy of several $\mu \mathrm{m}$ (presented in Figure 4). In order to obtain an accurate, quantified combined misalignment, the Non-DriveEnd (NDE) bearing of the IM and the bearings of the load machine must be located on a perfect straight line. Because there is only one degree of freedom in the system (the AMB), not all combined misalignments can be reproduced.

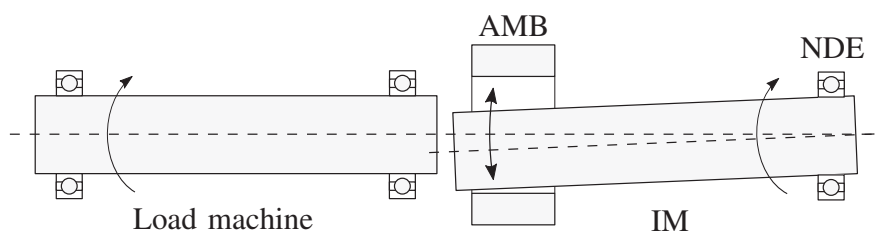

Figure 4: Implying combined misalignment with the AMB

As misalignment in terms of rotor-movement is nothing more then a static eccentricity, the AMB-set-points $\mathrm{d} x$ and $\mathrm{d} y$ where the AMB is axially located can be written as a constant function in time for a specified direction:

$$
\begin{aligned}
& \mathrm{d} x=A_{\text {mis,hor }} \\
& \mathrm{d} y=A_{\text {mis,ver }}
\end{aligned}
$$

With:

$$
\begin{array}{ll}
\mathrm{d} x & \text { set-point AMB horizontal; } \\
\mathrm{d} y & \text { set-point AMB vertical; } \\
A_{\text {mis,hor }} & \text { eccentricity in horizontal direction; } \\
A_{\text {mis,ver }} & \text { eccentricity in vertical direction; }
\end{array}
$$

and:

$$
A_{\mathrm{mis}}=\sqrt{A_{\mathrm{mis}, \mathrm{hor}}^{2}+A_{\mathrm{mis}, \mathrm{ver}}^{2}} \text { total static eccentricity. }
$$

Misalignment is usually not defined by the term $A_{\text {mis }}$, but by the terms offset and gap difference (graphically presented in Figure 5). In the literature, offset could be expressed as rim and gap difference was occasionally noted as face. Face and rim were commonly used before misalignment was measured with laser-technology. Those terms where in fact the values that could be read-off the dials in the older, alternative measuring-methods. Following Figure 5, the relation between the magnitude of misalignment, $A_{\mathrm{mis}}$ and the offset, $c_{\mathrm{offset}}$, can be expressed as follows:

$$
A_{\mathrm{mis}}=\frac{x_{2}}{x_{1}} c_{\mathrm{offset}}
$$

With:

$$
\begin{aligned}
& x_{1} \text { between NDE bearing and shaft end at DE; } \\
& x_{2} \text { between NDE bearing and DE bearing. }
\end{aligned}
$$

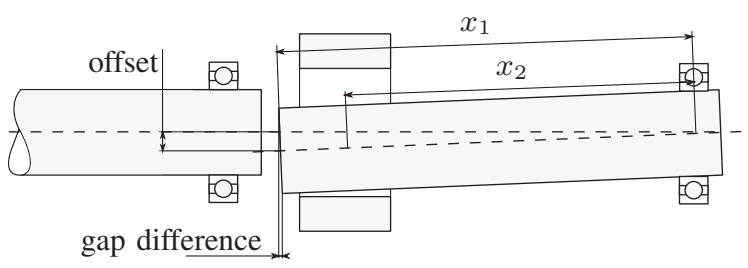

Figure 5: Misalignment defined by offset and gap difference

Due to the single degree of freedom system, the gap difference, $c_{\text {gapdiff, }}$ can be expressed as a function of $c_{\text {offset }}$ and the shaft diameter $d_{\mathrm{r}}$ :

$$
\begin{aligned}
c_{\text {gapdiff }} & =d_{\mathrm{r}} \cdot \sin \left[\arctan \left(\frac{c_{\text {offset }}}{x_{1}}\right)\right] \\
& =\frac{d_{\mathrm{r}}}{\sqrt{1+\frac{x_{1}^{2}}{c_{\text {offset }}^{2}}}}
\end{aligned}
$$

To summarize, misalignment $A_{\text {mis }}$ can be expressed as a function of offset or gap difference by following equations:

$$
A_{\text {mis }}=\left\{\begin{array}{l}
\frac{x_{2}}{x_{1}} c_{\text {offset }} \\
\frac{x_{2}}{\sqrt{1-\frac{d_{\mathrm{r}}^{2}}{c_{\text {gapdiff }}^{2}}}}
\end{array}\right.
$$

With the use of previous equations, the severity (or magnitude) of misalignment and its reflection in the stator current can easily be investigated. The variables $c_{\text {offset }}$ or $c_{\text {gapdiff }}$ immediately result in specific set points $\mathrm{d} x$ and $\mathrm{d} y$ for the AMB. When static eccentricity is applied into the IM, a reflection of that deviation is present in the stator current. Due to the misalignment, the air-gap is not uniformly divided throughout the machine. This abnormally division of air-gap is magnetically equivalent to a change of the flux-linkage between the stator and the rotor. Consequently, due to the change of flux-linkage, the misalignment can be visualized in the machine's stator current. The reflection of misalignment in 
the current propagates on a specific frequency, modulated on the fundamental current-frequency. Performing a frequencyanalysis makes it fairly easy to detect misalignment in the stator current. The specific fault-frequency $f_{\text {stat,ecc }}$ can be written as, [15]-[17], [20], [21]:

$$
f_{\text {stat }, \mathrm{ecc}}=v \cdot f_{1} \pm R S \cdot k \cdot f_{\mathrm{r}}
$$

With:

$\begin{array}{ll}f_{1} & \text { the fundamental current frequency; } \\ f_{\mathrm{r}} & \text { the rotational speed frequency; } \\ v & \text { harmonic order } 1,3,5,7 \ldots ; \\ k & \text { harmonic order } 1,2,3,4 \ldots ; \\ R S & \text { number of rotor slots. }\end{array}$

\section{B. Mechanical unbalance}

Due to imperfections, any operating IM is always severing mechanical unbalance due to mass-eccentricity. Figure 6 presents the definition of an eccentric mass. Aside the geometric position of the rotor, once the gravitational center-point of the rotor deviates from the rotational center, mass-eccentricity can be defined. The quantification of the unbalance is done by defining a certain equivalent mass-unbalance, $m_{\text {unb,eq }}$, and a gravitational radius of that mass, $r_{\text {unb }}$. By coupling direct loads onto the shaft of the machine (e.g. pulleys, gears, sprockets), the unbalance is increased insuperable. Unbalance is fairly easy to identify by vibration analysis, because the eccentric mass generates an alternating force on the bearings and so on the stator housing (proportional with the measured acceleration). In order to detect the mass-unbalance in the stator current, an air gap variation must be imposed between the stator and the rotor. That variation is generally induced by the unbalance force reacting onto the bearings, as they act as a simplified spring-system. The specific stiffness of the springsystem can be provided by the bearing-supplier. The result of the propagation of the unbalanced force on the bearings is in fact a classic example of dynamic eccentricity (see Figure 1, right). Therefore, in a first approach, mass-eccentricity will be emulated by applying a dynamic eccentricity onto the machine.

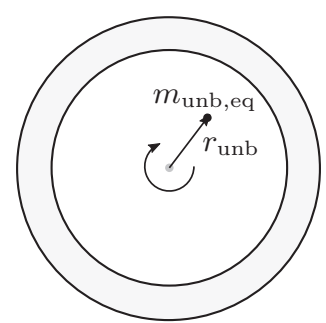

Figure 6: The quantification of mass-unbalance in a rotational system.

As the unbalance induces a dynamic eccentricity, the specific rotor-movements $\mathrm{d} x$ and $\mathrm{d} y$ are obtained by following time-based trigonometric formulas:

$$
\begin{aligned}
& \mathrm{d} x=A_{\text {unb }} \cdot \sin \left(2 \cdot \pi \cdot f_{\mathrm{r}} \cdot t\right) \\
& \mathrm{d} y=A_{\text {unb }} \cdot \sin \left(2 \cdot \pi \cdot f_{\mathrm{r}} \cdot t+\frac{\pi}{2}\right)
\end{aligned}
$$

With:

$$
\begin{array}{ll}
A_{\text {unb }} & \text { magnitude of dynamic eccentricity; } \\
t & \text { time. }
\end{array}
$$

Now, the only unknown parameter in obtaining the rotormovements for every mass-unbalance is the magnitude of the

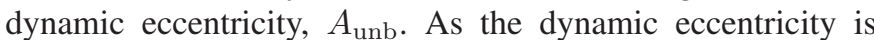
induced due to the centrifugal force originated by the massunbalance, it can be calculated as follows:

$$
A_{\mathrm{unb}}=\frac{F_{\mathrm{unb}}}{k_{\mathrm{rad}, \mathrm{DE}}}=\frac{4 \cdot \pi^{2} \cdot m_{\mathrm{unb}, \mathrm{eq}} \cdot r_{\mathrm{unb}} \cdot f_{\mathrm{r}}^{2}}{k_{\mathrm{rad}, \mathrm{DE}}}
$$

With:

$$
\begin{array}{ll}
F_{\text {unb }} & \text { centrifugal/unbalance force; } \\
k_{\text {rad,DE }} & \text { radial DE bearing stifness. }
\end{array}
$$

Similar to static eccentricity, dynamic eccentricity creates as well an unique signature in the current. Logically, as a clear air-gap variation is imposed between the rotor and stator. When a mass-unbalance is applied, the fault-frequency, $f_{\text {dyn,ecc }}$, in the stator current's spectrum can be written as (11) according to [15]-[17], [20] (With the harmonic $n=$ $1,2,3,4 \ldots)$.

$$
f_{\text {dyn }, \text { ecc }}=v \cdot f_{1} \pm(R S \cdot k \pm n) f_{\mathrm{r}}
$$

Note: In practice, due to many imperfection, rotating unbalance is (similar to misalignment) unavoidable. Because of this fact, the International Standard Organization created the ISO 21940-11:2016 in which tolerable limits are defined for mechanical unbalance in all kinds of applications (rotors with rigid behavior, [22]). Conclusively, both misalignment and mass-unbalance are unavoidable. This means that the combination of static and dynamic eccentricity is ever-present in every electric rotating machine. This combination of these eccentricities is, as mentioned in §II, called mixed eccentricity. The signature of mixed eccentricity in the stator current's spectrum, $f_{\text {mix }, \text { ecc }}$, is defined as:

$$
f_{\text {mix }, \text { ecc }}=f_{1} \pm k \cdot f_{\mathrm{r}}
$$

As can be observed, the mixed eccentricity faultcomponents are the modulation of the rotational speed with the fundamental current-frequency. Due to the always-present components described in (12), the speed can easily be estimate out of the current's spectrum. One condition to apply this technique is a sufficient accurate current spectrum. This can be obtained by measuring long enough, applying a good frequency transformation (such as [23]) and solving the Picket Fence Effect, [24].

\section{MaGnetiC BEARING AS A FAULT-EMUlATOR}

The rotor/stator-movements are defined for numerous misalignment and mass-unbalance faults. This knowledge creates the opportunity of emulating those bearing faults in an electric machine. This goal can only be achieved when those specific rotor-movements can be imposed on a machine with high precision. As mentioned in $\S \mathrm{I}$ and conceptually presented in Figure 7, an IM's DE bearing is replaced by an AMB in order 
to introduce the fault-related rotor-movements. However, the magnetic bearing must be able to take over the key functionalities of the original mechanical bearing. This contains e.g. counter-forcing gravity, the rotor's mechanical unbalance, the UMP, other imposed external forces... Those forces and the desired rotor-movements determines the power-range and so the physical dimensions of the bearing, [14], [25], [26]. Further extensive research on the AMB as a fault-emulator can be found in [14]. Throughout extensive simulations and fine-tuning of the proposed system, the magnetic bearing was actually built and implemented in the $11 \mathrm{~kW}$ IM, as can be seen in Figure 8.

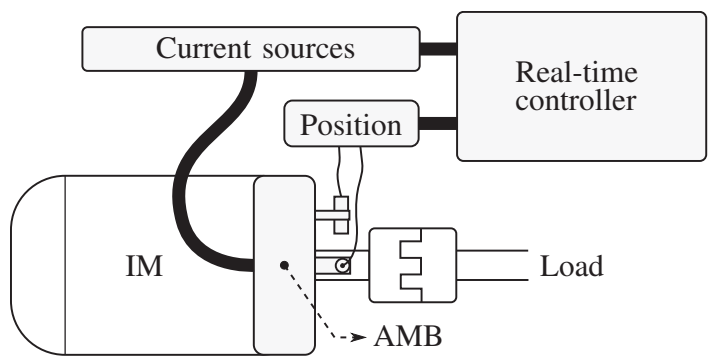

Figure 7: Concept of an AMB as a mechanical fault emulator

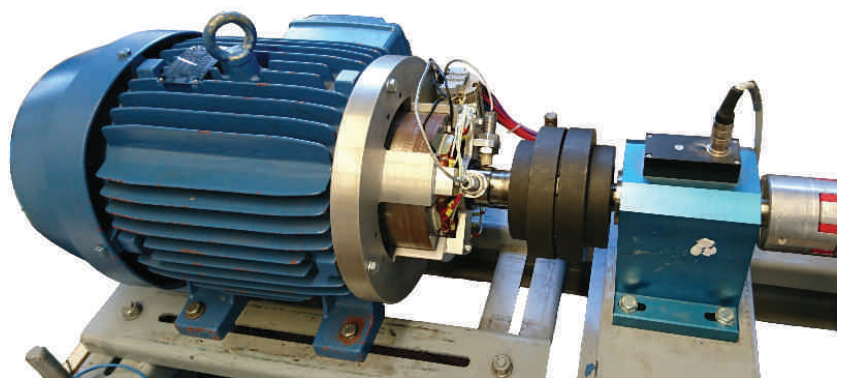

Figure 8: The AMB implemented at DE-side of the IM

\section{EXPERIMENTS}

Two experiments are conducted. One on the propagation of misalignment and the other on the manifestation of mechanical unbalance. For both experiments, an attempt is made to estimate the relation between the severity of the problem and the corresponding fault-signatures in the stator current. In order to spot the trends in the stator current's spectrum while adapting the fault's severity, a continuous logging of the stator current is executed. During that logging, the stator current's time-signal is transformed to the frequency-domain for every time-slot of 10s. Once one of the frequency-components does change significantly with respect to the previous measurement, that frequency-component is tracked throughout the whole measurement-campaign.

\section{A. Misalignment}

The rotor's shaft is moved by the AMB in the horizontal direction from $-400 \mu \mathrm{m}$ to $+400 \mu \mathrm{m}$ with respect to the stator's geometric center. The vertical position of the rotor is kept steady at the horizontal centerline of the stator. The current is measured and analyzed every 10s per step of $5 \mu \mathrm{m}$. Those signals are transformed to the frequency-spectrum and all frequency-components are analyzed as a function of the misalignment. The components of which a certain trend could be detected are plotted in Figure 9 and listed in Table I. As can be observed in the figure and as well in the table, the trending current-components clearly have a quadratic relation with the severity of misalignment, $A_{\text {mis }}$. More specific, the dominant components are related to Rotor Mixed Eccentricity (coefficient of determination: $r^{2}=0.84$ ) and Rotor Static Eccentricity $\left(r^{2}=0.72\right)$. Conclusively, a strong correlation can be observed between the misalignment and both static and mixed eccentricity. The parameters of the quadratic functions listed in Table I provide a quantified relation between the severity of the misalignment and the magnitude of the faultcomponents in the stator current.

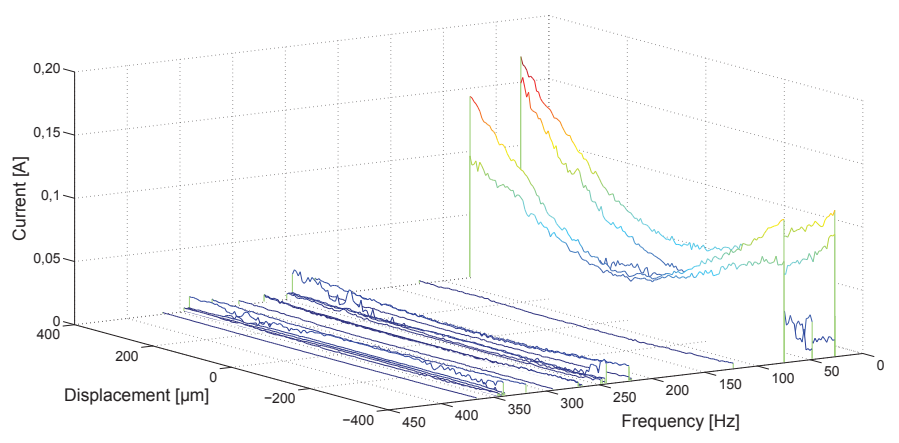

Figure 9: Varying frequency components during the emulation of misalignment/static eccentricity.

\section{B. Mechanical unbalance}

Changing the severity of the mass-unbalance is in this experiment done by adapting the mass, $m_{\mathrm{unb} \text {,eq }}$, while keeping the other parameters as a constant $\left(r_{\text {unb }}=100 \mathrm{~mm}, k_{\text {rad,DE }}=\right.$ $\left.2.85 \cdot 10^{5} \mathrm{kN} / \mathrm{mm}, f_{\mathrm{r}}=24.085 \mathrm{~Hz}\right)$. The mass is changed from $0 \mathrm{~kg}$ to $1.6 \mathrm{~kg}$ in steps of $10 \mathrm{~g}$. Similar to the experiment regarding misalignment, the current is measured and analyzed every step. The stator current's frequency-components which have a clear relation with the mass-unbalance are visualized in Figure 10 and listed in Table II. Again, a clear relation can be observed between the severity of the mass-unbalance, $A_{\mathrm{unb}}$, and the current components, but this time following a proportional function. The dominant fault-components are related with Rotor Mixed Eccentricity $\left(r^{2}=0.91\right)$ and Rotor Dynamic Eccentricity $\left(r^{2}=0.71\right)$. The trending frequency components confirm a clear and strong relation between both mixed and dynamic eccentricity and the emulated mass-unbalance. The listed parameters of the linear functions in Table II can be used to estimate a degree of severity out of the current components.

\section{CONCLUSION}

In this paper, a successful attempt was made to clearly quantify the relation between the severity of both misalignment and mass-unbalance and the stator current fault-signatures. 


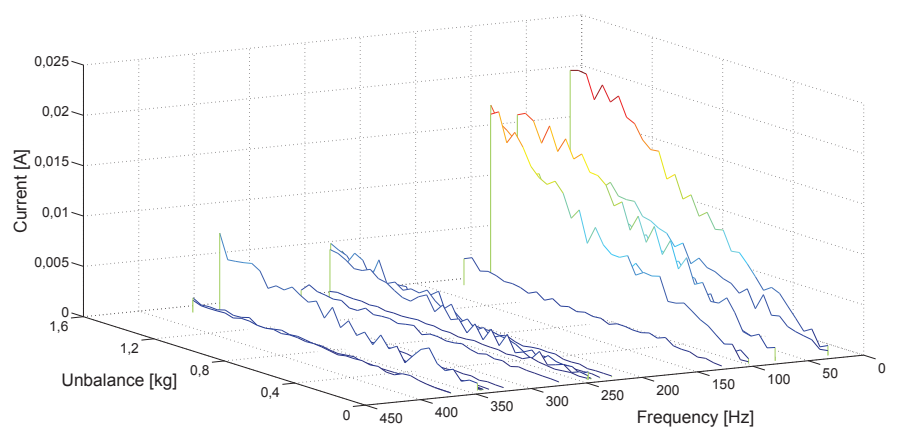

Figure 10: Varying frequency components during the emulation of mass-unbalance/dynamic eccentricity.

Both faults were analytically defined and an innovative testrig, consisting of a programmable magnetic bearing, was used in order to induce those fault-related rotor-movements into an $11 \mathrm{~kW}$ induction machine. From theory and the experimental results, it is clearly observed that the severity of misalignment is strongly related with static eccentricity (coefficient of determination $r^{2}=0.72$ ). The severity of mass-unbalance is equally related to dynamic eccentricity (coefficient of determination $r^{2}=0.71$ ). Furthermore, both faults have an intense relation with rotor mixed eccentricity, because the coefficient of determination is respectively $r^{2}=0.84$ and $r^{2}=0.91$ for misalignment and mass-unbalance. However, it is remarkable that by linearly increasing $A_{\text {mis }}$, the frequencycomponents are trending quadratic while by linearly increasing $A_{\text {unb }}$, the frequency-components are as well trending linearly. Nevertheless, the severity of both faults are unambiguously quantified with the stator current's fault-components by strong correlation.

\section{REFERENCES}

[1] G. B. Kliman, W. J. Premerlani, B. Yazici, R. a. Koegl, and J. Mazereeuw, "Sensorless, online motor diagnostics," IEEE Computer Applications in Power, vol. 10, no. April, pp. 39-43, 1997.

[2] W. T. Thomson and M. Fenger, "Current signature analysis to detect induction motor faults," IEEE Industry Applications Magazine, vol. 7, no. August, pp. 26-34, 2001.

[3] R. R. Schoen, T. G. Habetler, F. Kamran, and R. G. Bartheld, "Motor bearing damage detection using stator current monitoring," IEEE Transactions on Industry Applications, vol. 31, no. 6, pp. 1274-1279, 1995.

[4] L. Eren and M. J. Devaney, "Bearing Damage Detection via Wavelet Packet Decomposition of the Stator Current," IEEE Transactions on Instrumentation and Measurement, vol. 53, no. 2, pp. 431-436, 2004.

[5] M. Delgado, G. Cirrincione, a. Garcia, J. a. Ortega, and H. Henao, "A novel condition monitoring scheme for bearing faults based on Curvilinear Component Analysis and hierarchical neural networks," International Conference on Electrical Machines 2012, pp. 2472-2478.

[6] W. Saadaoui and K. Jelassi, "Induction motor bearing damage detection using stator current analysis," 2011 International Conference on Power Engineering, Energy and Electrical Drives, no. May, pp. 1-6, 2011.
[7] W. Z. W. Zhou, B. L. B. Lu, T. Habetler, and R. Harley, "Incipient Bearing Fault Detection via Motor Stator Current Noise Cancellation Using Wiener Filter," IEEE Transactions on Industry Applications, vol. 45, no. 4, pp. 1309-1317, 2009.

[8] M. J. Devaney and L. Eren, "Detecting motor bearing faults: Monitoring an induction motor's current and detecting bearing failure," IEEE Instrumentation and Measurement Magazine, vol. 7, pp. 30-50, 2004.

[9] L. Frosini and E. Bassi, "Stator current and motor efficiency as indicators for different types of bearing faults in induction motors," IEEE Transactions on Industrial Electronics, vol. 57, no. 1, pp. 244-251, 2010.

[10] B. Corne, C. Debruyne, P. De Baets, and J. Desmet, "Stator current measurements as a condition monitoring technology - The-state-of-theart," in 2014 International Conference on Electrical Machines (ICEM). Ieee, sep 2014, pp. 1659-1665.

[11] S. McInerny and Y. Dai, "Basic vibration signal processing for bearing fault detection," Education, IEEE Transactions on, vol. 46, no. 1, pp. 149-156, 2003. [Online]. Available: http://ieeexplore.ieee.org/xpls/abs_all.jsp?arnumber=1183679

[12] J. R. Stack, T. G. Habeter, and R. G. Harley, "Fault classification and fault signature production for rolling element bearings in electric machines," IEEE Transactions on Industry Applications, vol. 40, no. 3, pp. 735-739, 2004.

[13] D. S. Shah and V. N. Patel, "A Review of Dynamic Modeling and Fault Identifications Methods for Rolling Element Bearing," Procedia Technology, vol. 14, no. November 2015, pp. 447-456, 2014.

[14] B. Corne, J. Knockaert, and J. Desmet, "Emulating bearing faults - a novel approach," in 2016 XXII International Conference on Electrical Machines (ICEM), Sept 2016, pp. 2223-2229.

[15] S. Nandi, T. C. Ilamparithi, S. B. Lee, and D. Hyun, "Detection of eccentricity faults in induction machines based on nameplate parameters," IEEE Transactions on Industrial Electronics, vol. 58, no. 5, pp. 1673-1683, 2011.

[16] M. Y. Kaikaa and M. Hadjami, "Effects of the simultaneous presence of static eccentricity and broken rotor bars on the stator current of induction machine," IEEE Transactions on Industrial Electronics, vol. 61, no. 5, pp. 2452-2463, may 2014.

[17] X. Li, Q. Wu, and S. Nandi, "Performance analysis of a three-phase induction machine with inclined static eccentricity," IEEE Transactions on Industry Applications, vol. 43, no. 2, pp. 531-541, 2007.

[18] G. Joksimovi, "Dynamic simulation of cage induction machine with air gap eccentricity," IEE Proceedings - Electric Power Applications, vol. 152, no. 4, p. 803, 2005.

[19] Electrical Apparatus Service Association, "Root Cause Failure Analysis," 2004.

[20] S. Nandi, R. M. Bharadwaj, and H. a. Toliyat, "Performance analysis of a three-phase induction motor under mixed eccentricity condition," IEEE Transactions on Energy Conversion, vol. 17, no. 3, pp. 392-399, 2002.

[21] H. Douglas, P. Pillay, and A. K. Ziarani, "A new algorithm for transient motor current signature analysis using wavelets," IEEE Transactions on Industry Applications, vol. 40, no. 5, pp. 1361-1368, 2004.

[22] International Standard Organization, "ISO 21940-11:2016 Mechanical vibration - Rotor balancing, Part 11: Procedures and tolerances for rotors with rigid behaviour," 2016.

[23] A. Brandt, Noise and Vibration Analysis: Signal Analysis and Experimental Procedures. John Wiley and Sons, Ltd, 2011.

[24] B. Corne, B. Vervisch, C. Debruyne, J. Knockaert, and J. Desmet, "Comparing mesa with vibration analysis in order to detect bearing faults - a case study," in 2015 IEEE International Electric Machines Drives Conference (IEMDC), May 2015, pp. 1366-1372.

[25] G. Schweitzer and E. H. Maslen, Magnetic Bearings. Springer Science and Business Media, 2009.

[26] J. Hillyard, Magnetic Bearings, Joint Advanced Student School. Technical University of Munich, 2006, no. April. 
Table I: Misalignment trending functions of the detected fault-components

\begin{tabular}{|c|c|c|c|c|c|c|}
\hline \multirow[b]{2}{*}{ Frequency $[\mathrm{Hz}]$} & \multirow[b]{2}{*}{ Indication } & \multirow[b]{2}{*}{$\begin{array}{l}\text { Order } \\
k(; n)\end{array}$} & \multicolumn{4}{|c|}{$f\left(d_{\mathrm{ecc}}\right)=a \cdot d_{\mathrm{ecc}}^{2}+b \cdot\left|d_{\mathrm{ecc}}\right|+c$} \\
\hline & & & $\begin{array}{c}a \\
\times \quad \mathrm{e}-05\end{array}$ & $\begin{array}{c}b \\
\mathrm{x} \mathrm{e}-03\end{array}$ & $\begin{array}{c}c \\
\mathrm{x} \mathrm{e}-03\end{array}$ & $r^{2}$ \\
\hline 24.74 & Rotor Mixed Eccentricity & -1 & 0.1364 & 0.0328 & 5.4302 & 0.9971 \\
\hline 46.38 & Stator Winding Shortcut & $8 ;-3$ & 0.0582 & -0.0682 & 2.1880 & 0.8255 \\
\hline 72.91 & Rotor Mixed Eccentricity & 1 & 0.1224 & 0.0439 & 3.2389 & 0.9949 \\
\hline 169.26 & Rotor Mixed Eccentricity & 5 & 0.0099 & -0.0033 & 0.1461 & 0.7291 \\
\hline 217.43 & Rotor Mixed Eccentricity & 7 & 0.0034 & -0.0013 & 0.0215 & 0.8443 \\
\hline 220.04 & Stator Winding Shortcut & $1 ;-5$ & 0.0130 & 0.0008 & 0.4587 & 0.9641 \\
\hline 241.52 & Rotor Mixed Eccentricity & 8 & 0.0342 & -0.0479 & 1.7455 & 0.8761 \\
\hline 265.61 & Rotor Mixed Eccentricity & 9 & 0.0024 & -0.0009 & 0.0130 & 0.8579 \\
\hline 313.78 & Rotor Mixed Eccentricity & 11 & 0.0008 & -0.0003 & 0.0093 & 0.6332 \\
\hline 328.66 & Rotor Static Eccentricity & $1 ;-13$ & 0.0450 & -0.0495 & 1.2691 & 0.7305 \\
\hline 337.86 & Rotor Mixed Eccentricity & 12 & 0.0049 & -0.0008 & 0.0094 & 0.8176 \\
\hline 361.95 & Rotor Mixed Eccentricity & 13 & 0.0015 & -0.0004 & 0.0068 & 0.7995 \\
\hline 415.38 & Stator Winding Shortcut & $1 ;-9$ & 0.0002 & -0.0740 & 0.0182 & 0.7631 \\
\hline 621.65 & Rotor Static Eccentricity & $1 ;-7$ & 0.0484 & -0.0521 & 1.2838 & 0.7370 \\
\hline 637.43 & Stator Winding Shortcut & $4 ;-15$ & 0.0002 & -0.0006 & 0.0369 & 0.8215 \\
\hline 816.87 & Rotor Static Eccentricity & $1 ;-3$ & 0.0231 & -0.0255 & 0.6571 & 0.7252 \\
\hline 914.55 & Rotor Static Eccentricity & $1 ;-1$ & 0.0834 & -0.0883 & 2.1289 & 0.7178 \\
\hline 938.63 & Rotor Dynamic Eccentricity & $1 ;-1 ; 1$ & 0.006 & -0.0066 & 0.1687 & 0.7171 \\
\hline 1109.91 & Rotor Static Eccentricity & $1 ; 3$ & 0.0400 & -0.0430 & 1.0587 & 0.7385 \\
\hline 1207.54 & Rotor Static Eccentricity & $1 ; 5$ & 0.0004 & -0.0005 & 0.0155 & 0.7149 \\
\hline 1402.94 & Rotor Static Eccentricity & $1 ; 9$ & 0.0089 & -0.0094 & 0.2281 & 0.7168 \\
\hline
\end{tabular}

Table II: Unbalance trending functions of the detected fault-components

\begin{tabular}{c|c|c|c|c|c}
\multirow{2}{*}{ Frequency $[\mathrm{Hz}]$} & \multirow{2}{*}{ Indication } & \multicolumn{3}{|c}{$f\left(l_{\text {pit }}\right)=a \cdot l_{\text {pit }}+b$} \\
& & Order & $a$ & $b$ & $r^{2}$ \\
\hline \hline 24.73 & Rotor Mixed Eccentricity & -1 & 6.6826 & -5.6466 & 0.9872 \\
\hline 72.93 & Rotor Mixed Eccentricity & 1 & 4.9495 & -2.9889 & 0.9913 \\
\hline 97.05 & Rotor Mixed Eccentricity & 2 & 4.9764 & -15.9334 & 0.9407 \\
\hline 121.35 & Rotor Mixed Eccentricity & 3 & 0.6504 & -0.0458 & 0.8284 \\
\hline 220.04 & Rotor Mixed Eccentricity & 7 & 0.4996 & -0.3491 & 0.8604 \\
\hline 231.70 & Rotor Static Eccentricity & $1 ;-15$ & 1.3934 & -7.8003 & 0.8192 \\
\hline 235.44 & Rotor Dynamic Eccentricity & $1 ;-9 ;-12$ & 0.7389 & -1.0374 & 0.8525 \\
\hline 241.66 & Rotor Mixed Eccentricity & 7 & 1.4596 & -0.5474 & 0.8734 \\
\hline 265.77 & Rotor Mixed Eccentricity & 9 & 0.4522 & -0.1187 & 0.8527 \\
\hline 333.11 & Rotor Dynamic Eccentricity & $1 ;-7 ;-12$ & 0.1348 & 0.1158 & 0.7767 \\
\hline 362.16 & Rotor Mixed Eccentricity & 13 & 0.3779 & -0.1580 & 0.9071 \\
\hline 840.90 & Rotor Dynamic Eccentricity & $1 ;-1 ;-3$ & 0.1347 & -1.0194 & 0.6415 \\
\hline 962.50 & Rotor Dynamic Eccentricity & $1 ;-1 ; 2$ & 0.1502 & -1.1670 & 0.5599 \\
\hline 988.88 & Rotor Dynamic Eccentricity & $1 ; 1 ;-1$ & 0.0709 & -0.4179 & 0.6229 \\
\hline 1037.09 & Rotor Dynamic Eccentricity & $1 ; 1 ; 1$ & 0.2313 & -1.8054 & 0.6699 \\
\hline 1061.21 & Rotor Dynamic Eccentricity & $1 ; 1 ; 2$ & 0.1708 & -1.2089 & 0.7345 \\
\hline 1205.83 & Rotor Dynamic Eccentricity & $1 ; 1 ; 8$ & 1.1044 & -6.2791 & 0.8230 \\
\hline 1403.61 & Rotor Static Eccentricity & $1 ; 9$ & 0.3354 & $-1,9111$ & 0.7678 \\
\hline & & & &
\end{tabular}

